\title{
Drug-Related Problems Identified in a Sample of Portuguese Institutionalised Elderly Patients and Pharmacists' Interventions to Improve Safety and Effectiveness of Medicines
}

\author{
Filipa Alves da Costa ${ }^{1,2,3} \cdot$ Luísa Silvestre $^{1} \cdot$ Catarina Periquito $^{1} \cdot$ Clara Carneiro $^{1}$. \\ Pedro Oliveira ${ }^{1} \cdot$ Ana Isabel Fernandes $^{1} \cdot$ Patrícia Cavaco-Silva $^{1}$
}

Published online: 8 March 2016

(c) The Author(s) 2016. This article is published with open access at Springerlink.com

\begin{abstract}
Background Currently, people live longer but often with poor quality of life. The decrease in healthy life-years is partly attributable to the institution of polypharmacy to treat various comorbidities.

Objectives The objectives of the study were to determine the prevalence and nature of drug-related problems (DRPs) in polypharmacy elderly patients residing in nursing homes and to test the acceptability of a pharmacist's intervention.

Methods An exposure cohort was constituted in three Portuguese nursing homes, where all polypharmacy (five or
\end{abstract}

Filipa Alves da Costa

alvesdacosta.f@gmail.com

Luísa Silvestre

luisa.jsilvestre@gmail.com

Catarina Periquito

catarinaperiquito@gmail.com

Clara Carneiro

ccarneiro@presidencia.pt

Pedro Oliveira

pedromaoliveira@hotmail.com

Ana Isabel Fernandes

aifernandes@egasmoniz.edu.pt

Patrícia Cavaco-Silva

patsilva@netcabo.pt

1 Centro de Investigação Interdisciplinar Egas Moniz (CiiEM), Almada, Portugal

2 Registo Oncológico Regional Sul (ROR-Sul), Instituto Português de Oncologia de Lisboa Francisco Gentil, E.P.E, Rua Professor Lima Basto, 1099-023 Lisboa, Portugal

3 ISCSEM, Campus Universitário, Quinta da Granja Monte de Caparica, 2829-511 Caparica, Portugal more medicines) elderly patients ( $\geq 65$ years of age) were analysed and then a random stratified sample was extracted to be subject to an intervention. Clinical and therapeutic data were collected and analysed for DRPs and classified according to the II Granada Consensus, by a pharmacist-led team. The intervention was the formulation of a pharmacist's recommendations to prescribers addressing clinically relevant DRPs, along with suggestions for therapy changes. Results The initial sample included 126 elderly patients taking 1332 medicines, where 2109 DRPs were identified. The exposure cohort included 63 patients, with comparable baseline data $(p>0.005)$. Manifest DRPs occurred in $31.7 \%$ of the intervention group (mainly quantitative ineffectiveness-DRP 4), whereas potential DRPs were identified in $100 \%$ of patients (mainly non-quantitative unsafe-DRP 5). Amongst the DRPs identified, 584 (56.7\%) were reported to prescribers (all types of DRPs) and $113(11 \%)$ to nurses (only non-quantitative ineffectiveness-DRP 3). A total of 539 pharmacist recommendations were presented to physicians, corresponding to 62 letters sent by mail, each including an average of 8.7 recommendations to solve DRPs present in intervention group (IG) patients. There was a high non-response rate $(n=34$ letters; $54.8 \%$; containing 367 pharmacist recommendations; $68.1 \%$ ) and amongst recommendations receiving feedback, only $8.7 \%$ of pharmacist recommendations made were accepted $(n=15)$. Positive responses were significantly associated with a lower number of recommendations made, whereas a higher number of recommendations increased the odds of no response $(p<0.001)$. Conclusion A pharmacist-led medication review proved useful in identifying DRPs in elderly polypharmacy nursing home residents. Stronger bonds must be developed between healthcare professionals to increase patient safety in the vulnerable institutionalised elderly population. 


\section{Key Points}

The Granada Classification for drug-related problems proved useful in guiding a pharmacist-led medication review in elderly patients.

Nearly three manifest drug-related problems were detected in polypharmacy elderly patients, which could have been prevented.

Collaboration between pharmacists, nurses and doctors can improve the rational use of medicines.

Effective communication with physicians may be fostered by reducing the number of pharmacist recommendations.

\section{Introduction}

For the past decades, people have been living longer. Portugal is currently one of Europe's leading countries in terms of life expectancy with an age index registered in 2014 of $138.6 \%$ [1]. This demographic change is attributable to various factors, where health technology plays an important role. Medicines are undoubtedly an effective tool to promote better health, provided they are rationally used. The current challenge for healthcare professionals has shifted from increasing people's life to achieving a better quality of life. The fact that Portugal's data on healthy life-years after age 65 years do not match the country ranking in terms of longevity is a cause of concern. Focus has centred on the use of potentially inappropriate medication (PIM) in elderly patients, which is in fact a type of drug-related problem (DRP). Various tools have been developed to identify PIM and to alert doctors to the most appropriate treatment, with the ultimate goal of achieving a more rational pharmacotherapy and better patient outcomes [2-4].

Pharmacist-led medication review is an area, within pharmaceutical care, currently attracting much attention, which can be performed using explicit or implicit criteria. Most of the interventions made in nursing homes use explicit criteria. These are much simpler to use when a type 1 medication review is undertaken [5], i.e. when all information is based exclusively on patient medical records and no information is obtained from the patient. Literature describing interventions in institutionalised elderly patients, where a medication review focusses on the identification of DRP, is very scarce and the few published studies have used different DRP classifications, making comparisons very difficult [6]. In Portugal, only three studies have been found evaluating DRPs in nursing homes, two of them focussing on the detection of PIM, either using the STOPP/START criteria [7] or Beers criteria [8]. The third study focussed on the use of the medication regimen complexity index, which measures the number of medicines and dosages, but not the quality of pharmacotherapy or its outcome [9]. Internationally, there are various papers published using different criteria for identifying PIM, but the Beers criteria are the most used worldwide. The START/STOPP criteria have been gaining prominence in Europe [10] and there are reports using the McLeod criteria [11], Priscus list [12] and even nationally developed classifications [13, 14]. However, few reports of pharmacist-led medication reviews focus on the identification of DRPs, and these have either used the Pharmaceutical Care Network Europe classification $[15,16]$ or the DOCUMENT classification [17]. The Dader method has been used in nursing homes [18] but, to our knowledge, no paper has yet described the nature of DRP detected using the Granada classification to guide pharmacist-led medication reviews $[19,20]$. Therefore, this study aimed at determining the prevalence of manifest and potential DRPs in polypharmacy elderly patients residing in nursing homes and to describe the nature of DRPs using the Granada classification. Furthermore, the study aimed to test the acceptability of a pharmacist's intervention intending to solve the DRPs detected.

\section{Methods}

\subsection{Study Design}

An exposure cohort was constituted in four Portuguese nursing homes, where all polypharmacy (five or more medicines) elderly patients ( $\geq 65$ years of age) were analysed and then a random stratified sample was extracted to be subject to an intervention. These were compared with the remaining, meeting the inclusion criteria, to assess representativeness.

\subsection{Sample of Nursing Homes}

Four nursing homes were invited to participate in the study, two located in Alentejo and another two in Lisboa and the Vale do Tejo region. Nursing homes were chosen using geographical convenience sampling. Data collection was primarily ensured by two trainee pharmacists, and each of them was responsible for two facilities. The location was chosen according to the place where they were practicing, as data collection was undertaken during their pre-registration training. Eligibility criteria were also defined for the nursing homes, including completeness of fundamental 
variables (primary diagnosis and prescribed therapy) in the medical records.

\subsection{Sample of Patients}

Eligible patients were polypharmacy (taking five or more medicines at the time of study) elderly patients ( $\geq 65$ years of age).

\subsection{Study Period}

The study started in October 2013. The interventions were carried out during August and September 2014 and results evaluated in October 2014.

\subsection{Collected Data}

All data analysed were retrieved from medical records and included sociodemographic information and clinical and therapeutic data (the latter checked in medication charts). Clinical data collected included: medical diagnoses, laboratory tests and measurements of clinical biomarkers, and eventual hospitalisations.

Medicines prescribed were classified according to the ATC (Anatomic Therapeutic Chemical) classification proposed by the World Health Organization [21].

Patients' medical conditions, negative outcomes and medicines used were analysed using information contained in the medical records and in medication charts.

DRPs were identified by two trainee pharmacists, who created a database with raw data and their findings. This database was subsequently reviewed by members of the research team specialised in pharmaceutical care, involving two clinical pharmacists and a physician. One of the reviewers (clinical pharmacist) checked all records, whilst the other two checked only records where there was uncertainty.
DRP were searched in all patients and, when present, classified according to the II Granada Consensus [19, 20], which divides DRPs into three main categories: necessity, effectiveness and safety (Fig. 1).

A negative outcome, defined as a manifest DRP, was considered when the medical record included information that allowed the researchers to verify that the problem had actually occurred, such as a raise in blood pressure (ineffectiveness) or the experience of an adverse drug reaction (safety). The remaining DRPs were considered as potential.

\subsection{Intervention}

The intervention consisted of the prioritisation of DRPs, a report of those identified and considered clinically relevant in the intervention group to prescribers and nurses, with the provision of a pharmacist's recommendation. This pharmacist's recommendation when headed for physicians could include suggestions of therapy changes if appropriate. Each recommendation could address one or various DRPs, as the pharmacist's recommendations could solve or prevent more than one DRP at the same time. The language used in the letters sent to physicians did not include the mention of DRPs in an effort to make it more meaningful to the target audience.

\subsection{Outcome Measures}

For all patients, the outcome measures were quantification and qualification of identified DRPs and their classification as potential or manifest. For the intervention group, process measures also included the number of DRPs reported and the number of pharmacist recommendations made to physicians; the proportion of pharmacist recommendations accepted was used as an outcome measure; Fig. 2 depicts the study schema.

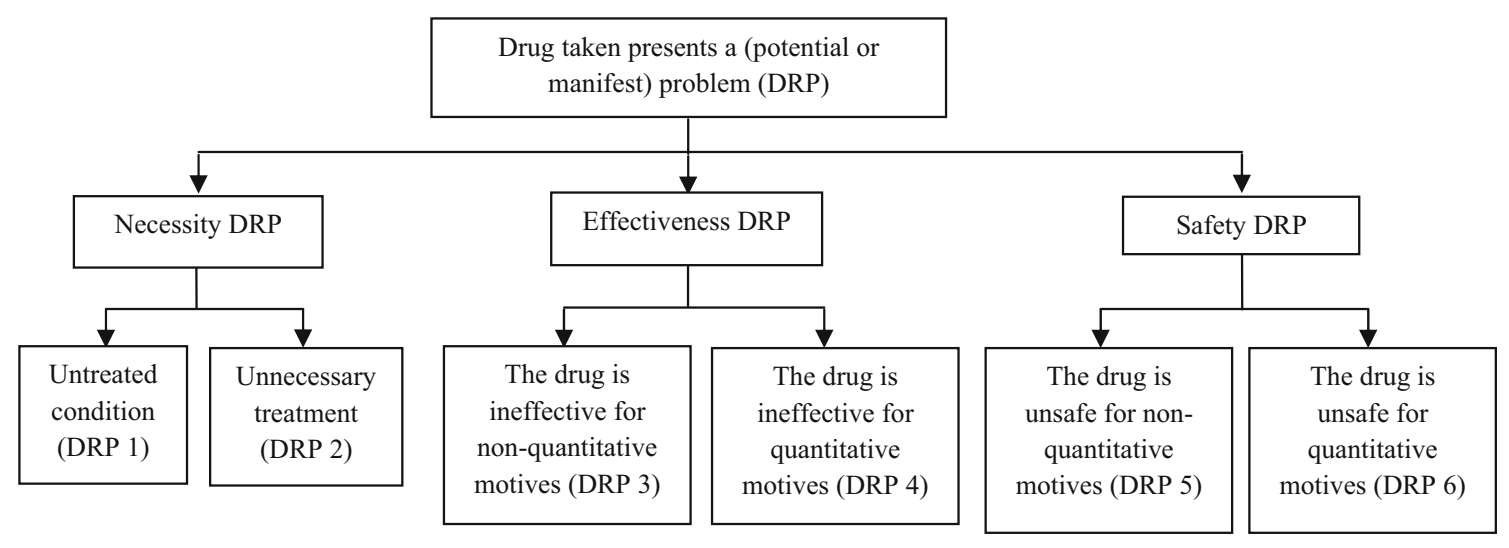

Fig. 1 Schematic of the II Granada Classification for drug-related problems (DRP) 


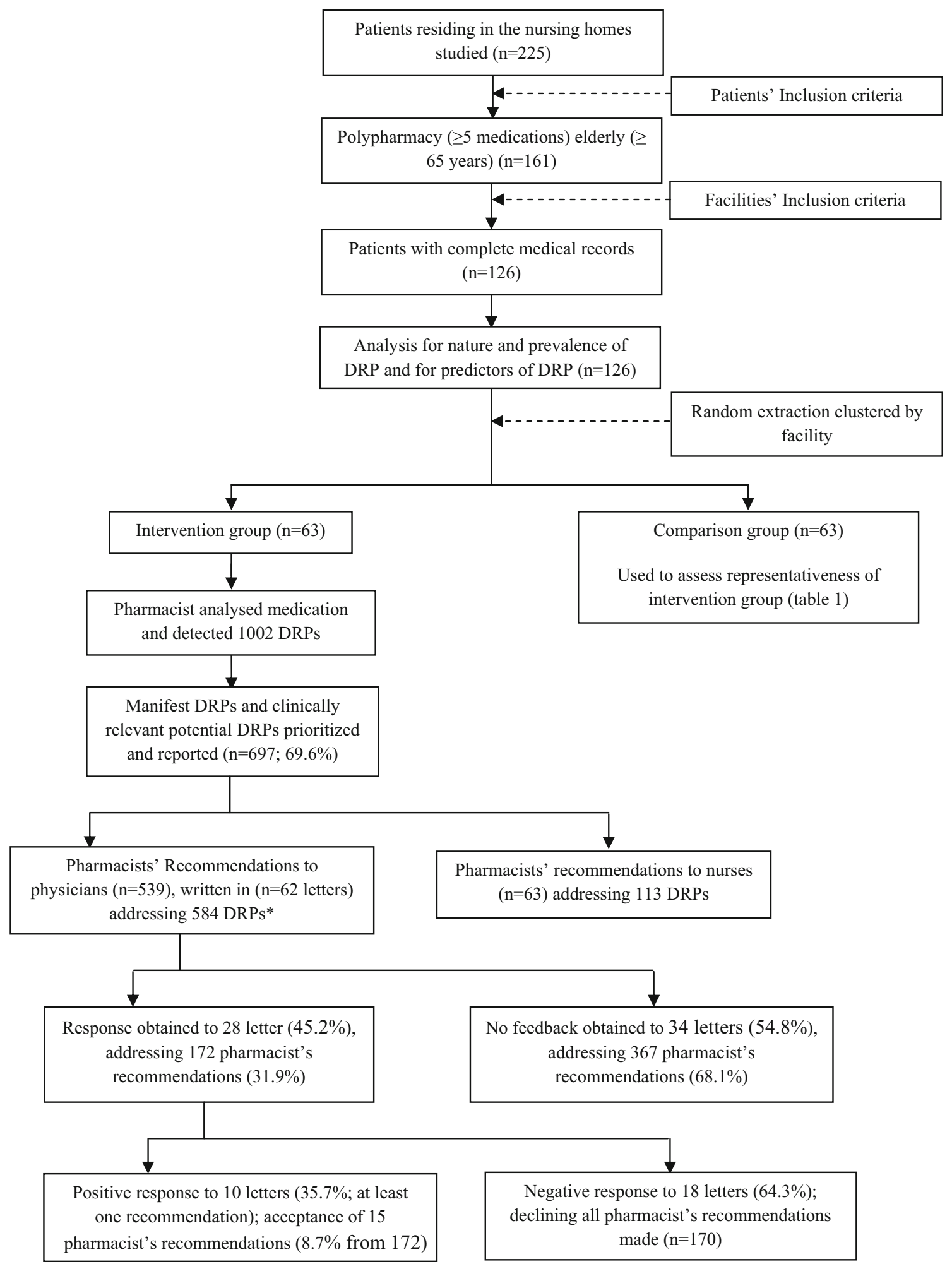

Fig. 2 Flow chart of study schema. DRP drug-related problems. *Note: Some pharmacist's recommendations addressed more than one DRP

\subsection{Data Analysis}

Data analysis was performed using the IBM software SPSS (IBM SPSS Statistics for Windows, IBM Corp, Armonk,
NY. Released 2012), version 21.0 and the main variables characterised using univariate analysis (relative and absolute frequencies for categorical variables and central tendency and dispersion measures for continuous variables). 
Bivariate analysis was used to answer hypotheses previously established. Because sample distribution was not normal (Kolmogorov-Smirnov test), mostly non-parametric tests were used and included the Chi-square test, Spearman's correlation coefficient and Mann-Whitney or Kruskal-Wallis tests, according to the type of variables. A confidence interval of $95 \%$ was considered for all tests.

\section{Results}

All four facilities invited accepted to participate in the study, totalling 225 elderly patients, of whom 161 patients met the inclusion criteria ( $\geq 65$ years of age, taking five or more medications). However, one facility, from Alentejo, was subsequently excluded because of data incompleteness, making the final group 126 polypharmacy elderly patients from three facilities in Portugal.

\subsection{Frequency and Nature of DRPs Identified (All Patients)}

The sample of 126 patients, taking a total of 1332 medicines, comprised mainly female individuals $(n=87$; $69 \%$ ), with a mean age of 84.8 years [standard deviation $(\mathrm{SD})=6.1$, median of four registered comorbidities and being treated with over ten medicines (median $=10$; mean $=10.6 ; \quad \mathrm{SD}=4.2$ ). A median of 14.5 DRPs $(\mathrm{SD}=8.4)$ were detected per patient, considering both potential and manifest.

Patients were randomly assigned to the intervention group using stratified sampling $(n=63)$, and their characteristics compared with the control group $(n=63)$ to assess representativeness (Table 1). Groups were shown to be comparable at baseline.

All 1332 medicines being taken by all polypharmacy patients $(n=126)$ were classified according to the ATC classification. Figure 3 depicts the pharmacotherapeutic classes more frequently involved in polypharmacy. The three leading groups found accounted for $75 \%$ of the drugs prescribed: central nervous system $(30.5 \%)$, cardiovascular system $(24.5 \%)$ and gastrointestinal tract $(19.8 \%)$.

All patients' demographic and medical characteristics were explored as potential determinants for polypharmacy. Data indicate that the number of comorbidities was moderately but significantly correlated with the number of prescribed medicines (Table 2).

All patients $(n=126)$ were assessed for potential or manifest DRP where a total of 2109 DRPs were identified. Every patient had at least one DRP. The most commonly found DRP belonged to the safety domain $(n=922$; $43.7 \%)$, followed by necessity $(n=727 ; 34.5 \%)$ and last by effectiveness $(n=460 ; 21.8 \%)$. Considering the second level of this classification, the order found was: unsafe drug (non-quantitative, DRP 5) $(n=741 ; 35.1 \%)$, unnecessary treatment (DRP 2) $(n=581 ; 27.6 \%)$, ineffective drug (nonquantitative, DRP 3$)(n=387 ; 18.4 \%)$, unsafe drug (quantitative, DRP 6$)(n=181 ; 8.6 \%)$, need for additional treatment (DRP 1) $(n=146 ; 6.9 \%)$ and last ineffective drug (quantitative, DRP 4) $(n=73 ; 3.5 \%)$.

Potential predictors of the occurrence of DRP were explored but only the number of comorbidities (Spearman's $r=0.412 ; p<0.001)$ and the number of prescribed medicines (Spearman's $r=0.766 ; p<0.001$ ) were found to be directly and significantly correlated, the latter exhibiting a strong correlation (Fig. 4).

Most of the identified DRPs were potential $(n=2064$; $97.9 \%)$ and only 45 were manifest $(2.1 \%)$. With regard to manifest DRPs, the majority was classified as DRP $4(n=27$; $60 \%)$, followed by DRP $6(n=9 ; 20 \%)$, DRP $1(n=5$; $11.1 \%)$, DRP $3(n=3 ; 6.7 \%)$ and DRP $5(n=1 ; 2.2 \%)$.

\subsection{Intervention Group}

Considering only the intervention group $(n=63)$, a total of 1002 DRPs were identified, of which, 697 (69.6\%) DRPs were reported. In total, 584 (83.8\%) DRPs were reported to the physician and $113(16.2 \%)$ were reported

Table 1 Baseline characteristics of 126 polypharmacy (five or more medicines) elderly ( $\geq 65$ years of age) Portuguese institutionalised patients

\begin{tabular}{|c|c|c|c|c|}
\hline Characteristic & Overall, $n=126$ & Intervention group, $n=63$ & Comparison group, $n=63$ & $p$ value \\
\hline $\operatorname{Sex}[n(\%)]$ & & & & 0.563 \\
\hline Female & $87(69)$ & $45(71.4)$ & $42(66.7)$ & \\
\hline Male & $39(31)$ & $18(28.6)$ & $21(33.3)$ & \\
\hline Age $[\mathrm{M}(\mathrm{SD})]$ & $84.8(6.1)$ & $85.16(6.3)$ & $84.5(6)$ & 0.525 \\
\hline No. of prescribed medicines [MD (SD)] & $10(4.2)$ & $10(4.6)$ & $9(3.9)$ & 0.818 \\
\hline Comorbidities [MD (SD)] & $4(2.1)$ & $4(2)$ & $4(2.3)$ & 0.670 \\
\hline No. of daily dosages [MD (SD)] & $11(6.2)$ & $11(7)$ & $11(5.5)$ & 0.868 \\
\hline No. of total DRP (potential and manifest) [MD (SD)] & $14.5(8.4)$ & $13(9.2)$ & $16(7.5)$ & 0.252 \\
\hline
\end{tabular}

$S D$ standard deviation, $M$ mean, $M D$ median 
Fig. 3 Drug classes more frequently involved in polypharmacy (five or more medicines) in 126 elderly ( $\geq 65$ years of age) institutionalised Portuguese patients

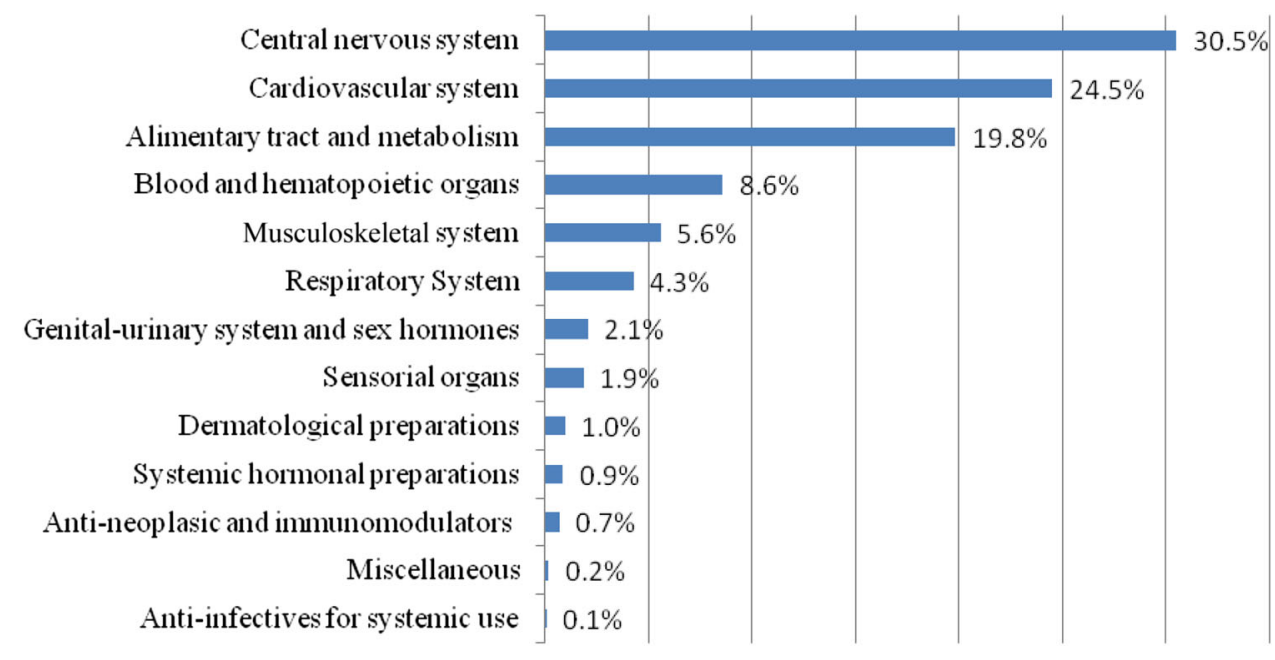

Table 2 Potential determinants of polypharmacy in 126 elderly ( $\geq 65$ years of age) Portuguese institutionalised patients

\begin{tabular}{llr}
\hline & No. of prescribed medicines & $p$ value \\
\hline Sex [MD; M (SD)] & & 0.494 \\
Female & $10 ; 10.6(3.9)$ & \\
Male & $9 ; 10.5(4.9)$ & 0.310 \\
Age [Pearson's correlation] & 0.092 & $<0.001$ \\
No. of comorbidities [Spearman's correlation] & 0.490 & \\
\hline
\end{tabular}

$S D$ standard deviation, $M$ mean, $M D$ median

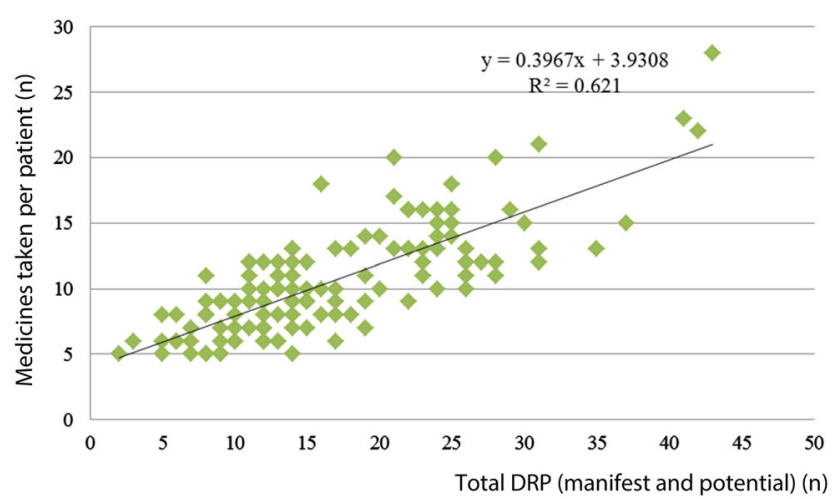

Fig. 4 Correlation between the number of prescribed medicines per patient and the presence of total drug-related problems (DRP, manifest and potential) in 126 polypharmacy (five or more medicines), elderly ( $\geq 65$ years of age), institutionalised Portuguese patients

to nursing staff. Reports to nurses were mainly based on changing administration times. Pharmacist recommendations to physicians resulted from the analysis of the 584 DRPs detected and included 539 suggestions to solve or prevent them, which could comprise dosage changes, suspension or addition of medicines, and request of additional complementary exams.

A total of 62 letters addressing 539 recommendations were made to physicians regarding the 63 polypharmacy elderly patients in the intervention group. Each letter reported 9.2 DRPs on average and contained 8.7 pharmacist recommendations (2-19). Considering all the pharmacist's recommendations sent $(n=539)$, response was only obtained to 172 of these (31.9\%). From responses obtained, only 15 pharmacist recommendations were accepted $(8.7 \%)$.

Analysing the number of recommendations made in the letters where a positive response was obtained, it is interesting to note that there is a significant association between these two variables (Table 3).

\section{Discussion}

Although the sample addressed in this study was achieved using a convenience strategy valuing geographical location, the sample characteristics were comparable to the reference population in the same regions, including gender distribution. The main difference referred to the age structure, as in the reference population, the larger age class included those aged from 65 to 69 years and diminished progressively every 5 years, whereas the study sample observed the opposite direction because the larger group was represented by those aged over 85 years [1]. This fact is not surprising because the sample group used 
Table 3 Association between the number of pharmacist recommendations made and physician response

\begin{tabular}{llll}
\hline & $\begin{array}{l}\text { Group 1: no feedback obtained to } \\
\text { pharmacist's recommendation }\end{array}$ & $\begin{array}{l}\text { Group 2: negative response to } \\
\text { pharmacist's recommendation }\end{array}$ & $\begin{array}{l}\text { Group 3: positive response to } \\
\text { pharmacist's recommendation }\end{array}$ \\
\hline $\begin{array}{l}\text { Total no. of } \\
\text { recommendations }\end{array}$ & 367 & 120 & 52 \\
$\begin{array}{l}\text { Mean no. of } \\
\text { recommendations }\end{array}$ & 10.79 & 6.67 & 5.20 \\
\hline
\end{tabular}

originated from nursing homes. Additionally, clinical and therapeutic data were also comparable because the medicines most consumed in the study sample were those used in the most prevalent chronic conditions reported in the National Health Enquiry [22].

Each elderly patient presented with a median of four comorbidities registered in the medical file, around half of the comorbidities reported elsewhere [23, 24]. Incomplete patient records are a possible explanation for this finding, which is consistent with the literature [25].

The initial sample was prescribed a mean of 11 medicines per day, varying between 5 and 18 , which is also similar to results published previously $[11,15,16,24,27$, 28].

A direct correlation between the number of comorbidities and the number of prescribed medicines $(r=0.490$; $p<0.001$ ) was found, as described before [29]. This is not surprising because, as more health conditions arise, the higher the need for additional therapy. However, no relation was found between the number of medicines and age, contradicting previous findings [18].

The number of DRPs identified in this study was considerably higher than what was expected based on previous literature [15, 26, 27, 30, 31]. However, it should be noted that most of these studies did not differentiate between potential and manifest DRPs and did not use the Granada classification, thus making comparison impossible. The fact that very few studies were found using this classification in nursing homes may be related to a publication bias because this classification is originally Spanish, and subsequently validated in Portuguese, whereas others more frequently found arise from English-speaking countries. Although the III Granada Consensus has been published for some time, we opted to use the II Consensus because this is the one adopted nationally, and the only one validated for use in Portugal [19, 20, 32].

The more frequently found DRP was DRP 5 (35.1\%), consistent with what has been described as "risk of adverse drug reactions" [33] and as "potential interactions" [16]. The second more frequent DRP was DRP 2, similar to what has been reported as "medicine with unclear indication" $[15,30]$. However, it should be noted that there was an enormous difference between potential and manifest DRPs, with the latter representing only $2 \%$ of all DRPs detected.
When analysing the types of DRPs, it becomes clear that an important proportion is attributable to DRP 5, indicating that most of the potential interactions detected by pharmacists are unlikely to happen. However, it could also be that they had not yet happened at the time, and to check it we would need a longer follow-up. This has been reported elsewhere [34] and thus the prioritised interventions focussed on manifest DRP or those considered clinically significant, which represented $70 \%$ of the total DRPs detected.

The possibility of information bias may not be disregarded as some patient files may not be totally updated or complete, as previously described [35]. This bias, if present, will have particular influence on DRP 2 detected, which may not be real but rather a result of missing information. In regard to DRP 5, it should be noted that there was no record found for notifications made to the pharmacovigilance system, which indicates that these were either not made, which is in line with the low level of reporting practiced in Portugal [36], or simply not recorded in the patient file.

The pharmacist recommendations made to physicians sought to address clinically relevant DRPs and included suggestions that could solve various DRPs by therapy changes-including the addition of new medicines, the suspension of others and dosage change-and/or additional monitoring, which is quite similar to what has been reported elsewhere [16, 26, 31].

Results shown indicate there were two main drawbacks in this study. The first was undoubtedly the high proportion of pharmacist recommendations for which no feedback was obtained. This could be a result of logistic problems or lack of cooperation between different healthcare providers. Our experience in this study strongly reinforces the latter, as most non-response cases arose from one of the facilities where this culture is still lacking. The second drawback of the study was the low proportion of accepted recommendations $(\leq 10 \%)$, even if only respondents are considered. However, two considerations are warranted. First, if we consider the unit of analysis as the letters sent to physicians, rather than the recommendations, and considering acceptance of at least one recommendation per letter, this value would rise to $35.7 \%$, suggesting this proportion of physicians may be more open to interdisciplinary 
collaboration, which may be seen as more encouraging for pharmacists willing to engage in such tasks. Second, and perhaps more important, is the fact that our data suggest there is a reverse association between the number of pharmacist recommendations directed at physicians and the odds of success, i.e. the higher the number of recommendations, the lower the response rate. This finding has important implications for practice as it suggests that for pharmacists to be successful they should be more selective when providing recommendations. Although our data may not be extrapolated, our experience suggests that a maximum of five recommendations should be made to increase the odds of acceptance $(p=0.008)$.

Ideally, the follow-up of these patients should have been prolonged to ensure that DRPs solved did not result in new DRPs, which needed additional interventions. Furthermore, more robust outcome measures would be needed to evaluate if DRPs solved resulted in a better health and quality of life for the patient, which is the ultimate goal of pharmaceutical care. However, it should be stressed that this study is innovative by using a simple classification, with vast use in primary care worldwide, particularly in Portuguese- and Spanish-speaking countries, but with so far little research published applying it in nursing homes residents. To our knowledge, there was only one publication describing the use of the Dader method in a similar sample, but which did not fully characterise the prevalence or type of DRP found [18].

\section{Conclusion}

Pharmacist-led medication review proved useful in identifying DRPs in polypharmacy elderly patients. Closer collaboration between healthcare professionals is needed to improve the acceptability of pharmacist interventions and consequently the proportion of problems solved. Moreover, it seems that, to be successful, the pharmacist should be more selective in the recommendations made.

\section{Compliance with Ethical Standards}

Ethical approval The study complied with all clinical research requirements in accordance with the Declaration of Helsinki. The use of patients' medical records was authorised by the clinical director of the nursing home upon signing of an informed consent form. Patients data were collected anonymously using their process code. No patient or facility is here identified. Ethics committee approval was obtained from "Comissão de Ética para a Investigação nas Áreas de Saúde Humana e Bem-Estar da Universidade de Évora".

Patient consent There was no informed consent collected from the patient as the patient was not contacted and all information was extracted anonymously from medical records. Additionally, interventions were tested as a measure of quality improvement approved by the facilities.
Funding No sources of funding were used to assist in the preparation of this study. All indirect costs involved in the study were entirely supported by the researchers.

Conflicts of interest Filipa Alves da Costa, Luisa Silvestre, Catarina Periquito, Clara Carneiro, Pedro Oliveira, Ana Isabel Fernandes and Patricia Cavaco-Silva have no affiliations that are directly relevant to the content of this study.

Open Access This article is distributed under the terms of the Creative Commons Attribution-NonCommercial 4.0 International License (http://creativecommons.org/licenses/by-nc/4.0/), which permits any noncommercial use, distribution, and reproduction in any medium, provided you give appropriate credit to the original author(s) and the source, provide a link to the Creative Commons license, and indicate if changes were made.

\section{References}

1. PORDATA. Indicadores de envelhecimento em Portugal. Available at: http://www.pordata.pt/Portugal/Indicadores+de+envelhe cimento-526. Accessed 10 Oct 2014.

2. American Geriatrics Society 2012 Beers Criteria Update Expert Panel. American Geriatrics Society updated Beers Criteria for potentially inappropriate medication use in older adults. J Am Geriatr Soc. 2012;60(4):616-31.

3. Gallagher P, Ryan C, Byrne S, Kennedy J, O'Mahony D. STOPP (Screening Toolo of Oldfer Person's Prescriptions) and START (Screening Tool to Alert doctors to Right Tretament) Consensus Validation. Int J Clin Pharmacol Ther. 2008;46(2):72-83.

4. Hanlon JT, Schmader KE, Samsa GP. A method for assessing drug therapy appropriateness. J Clin Epidemiol. 1992;45: 1045-51.

5. Pharmaceutical Care Network Europe. PCNE guidelines for retrospective medication review in pharmacy V0, the official PCNE definition 2012. Available from: http://www.pcne.org. Accessed 15 Sept 2013.

6. van Mil JWF, Westerlund LOT, Hersberger KE, Schaefer MA. Drug-related problem classification systems. Ann Pharmacother. 2004;38:859-67.

7. Silva C, Ramalho C, Luz I, Monteiro J, Fresco P. Drug-related problems in institutionalized, polymedicated elderly patients: opportunities for pharmacist intervention. Int $\mathrm{J}$ Clin Pharm. 2015;37(2):327-34.

8. de Oliveira Martins S, Soares MA, van Mil JWF, Cabrita J. Inappropriate drug use by Portuguese elderly outpatients: effect of the Beers criteria update. Pharm World Sci. 2006;28(5): 296-301.

9. Advinha AM, de Oliveira-Martins S, Mateus V, Pajote SG, Lopes MJ. Medication regimen complexity in institutionalized elderly people in an aging society. Int J Clin Pharm. 2014;36(4):750-6.

10. Frankenthal D, Lerman Y, Kalendaryev E, Lerman Y. Intervention with the screening tool of older persons potentially inappropriate prescriptions/screening tool to alert doctors to right treatment criteria in elderly residents of a chronic geriatric facility: a randomized clinical trial. J Am Geriatr Soc. 2014;62(9):1658-65.

11. Stafford AC, Alswayan MS, Tenni PC. Inappropriate prescribing in older residents of Australian care homes. J Clin Pharm Ther. 2011;36(1):33-44.

12. Lochner S, Kirch W, Schindler C. Managing hypertension among nursing-home residents and community-dwelling elderly in Germany: a comparative pharmacoepidemiological study. Eur J Clin Pharmacol. 2012;68(5):867-75. 
13. Milos V, Rekman E, Bondesson A, Eriksson T, Westerlund T, Midlov P. Improving the quality of pharmacotherapy in elderly primary care patients through medication reviews: a randomised controlled study. Drugs Aging. 2013;30(4):235-46.

14. Chang CB, Lai HY, Yang SY, Wu RS, Liu HC, Hsu HY, Hwang SJ, Chang DC. Patient- and clinic visit-related factors associated with potentially inappropriate medication use among older home healthcare service recipients. PLoS One. 2014;9(4):e94350.

15. Davidsson M, Vibe OE, Ruths S, et al. A multidisciplinary approach to improve drug therapy in nursing homes. J Multidiscip Healthc. 2011;4:9-13.

16. Brulhart MI, Wermeille JP. Multidisciplinary medication review: evaluation of a pharmaceutical care model for nursing homes. Int J Clin Pharm. 2011;33(3):549-57.

17. Gheewala PA, Peterson GM, Curtain CM, Nishtala PS, Hannan PJ, Castelino RL. Impact of the pharmacist medication review services on drug-related problems and potentially inappropriate prescribing of renally cleared medications in residents of aged care facilities. Drugs Aging. 2014;31(11):825-35.

18. Oliveira MPF, Novaes MRCG. Drug-related problems in institutionalized elderly in Brasilia, Brazil. Biomed Aging Pathol. 2011;1(3):179-84.

19. Committee Consensus. Segundo Consenso de Granada sobre Problemas Relacionados con Medicamentos. Ars Pharmaceutica. 2002;43(3-4):175-84.

20. Santos H, Iglésias P, Fernández-Llimós F, Faus MJ, Rodrigues LM. Segundo Consenso de Granada sobre Problemas Relacionados com Medicamentos. Tradução intercultural de Espanhol para Português (europeu). Acta Med Port. 2004;17:59-66.

21. WHO Collaborating Centre for Drug Statistics Methodology. Guidelines for ATC classification and DDD assignment 2014. Oslo. ISBN 978-82-8082-596-4.

22. INE and INSA (2009). Inquérito Nacional de Saúde 2005/2006. Lisboa-Portugal. Available at http://www.insa.pt/sites/INSA/ Portugues/Publicacoes/Outros/Documents/Epidemiologia/INS_ 05_06.pdf. Accessed 22 Sept 2014.

23. Chan DC, Chen JH, Kuo HK, We CJ, Lu IS, Chiu LS, Wu SC. Drug-related problems (DRPs) identified from geriatric medication safety review clinics. Arch Gerontol Geriatr. 2012;54(1):168-74.

24. Stafford AC, Tenni PC, Peterson GM, Jackson SL, Hejlesen A, Villesen C, Rasmussen M. Drug-related problems identified in medication reviews by Australian pharmacists. Pharm World Sci. 2009;31(2):216-23.
25. Brown EL, Raue PJ, Mlodzianowski AE, Meyers BS, Greenberg RL, Bruce ML. Transition to home care: quality of mental health, pharmacy, and medical history information. Int J Psychiatry Med. 2006;36(3):339-49.

26. Halvorsen KH, Ruths S, Granas AG, et al. Multidisciplinary intervention to identify and resolve drug-related problems in Norwegian nursing homes. Scand J Prim Health Care. 2010;28(2):82-8.

27. Nishtala P, McLachlan AJ, Bell JS, Chen TF. A retrospective study of drug-related problems in Australian aged care homes: medication reviews involving pharmacists and general practitioners. J Eval Clin Pract. 2011;17(1):97-103.

28. Olesen C, Harbig P, Buus KM, Barat I, Damsgaard EM. Impact of pharmaceutical care on adherence, hospitalisations and mortality in elderly patients. Int J Clin Pharm. 2014;36(1):163-71.

29. Ramanath KV, Nedumballi S. Assessment of medication-related problems in geriatric patients of a rural tertiary care hospital. J Young Pharm. 2012;4(4):273-8.

30. Finkers F, Maring JG, Boersma F, et al. A study of medication reviews to identify drug-related problems of polypharmacy patients in the Dutch nursing home setting. J Clin Pharm Ther. 2007;32(5):469-76.

31. Alldred DP, Zermansky AG, Petty DR, Raynor DK, Freemantle $\mathrm{N}$, Eastaugh J, Bowie P. Clinical medication review by a pharmacist of elderly people living in care homes: pharmacist interventions. Int J Pharm Pract. 2007;15(2):93-9.

32. Consensus Committee. Tercer Consenso de Granada sobre Problemas Relacionados con Medicamentos (PRM) y Resultados Negativos asociados a la Medicacion (RNM). Ars Pharm. 2007;48(1):5-17.

33. Ruths S, Straand J, Nygaard HA. Multidisciplinary medication review in nursing home residents: what are the most significant drug-related problems? The Bergen District Nursing Home (BEDNURS) Study. Qual Saf Health Care. 2003;12(3):176-80.

34. Jankel CA, Fitterman LK. Epidemiology of drug-drug interactions as a cause of hospital admissions. Drug Saf. 1993;9(1):51-9.

35. Azevedo A, Domingues B, Pimenta da Rocha R, Eiriz R, Xavier V. Quality assessment of long-term prescription records: QMP Study. Acta Med Port. 2014;27(5):561-7.

36. Batel-Marques F, Alves C, Penedones A, Dias P, Martins A, Santiago LM, Fontes-Ribeiro C, Caramona M, Macedo T. Pharmacovigilance in Portugal: activity of the Central Pharmacovigilance Unit. Acta Med Port. 2015;28(2):222-32. 